\title{
The Prevalence of Pseudoexfoliation Syndrome and Pseudoexfoliation Glaucoma in South Kashmir
}

\author{
Asif Amin Vakil, M.S., ${ }^{1}$ Sheikh Sajad, M.S., M.Ch. ${ }^{2}$ \\ 'B-Grade Ophthalmology Specialist, J\&K Health Services, ${ }^{2}$ Associate Professor, Department of Ophthalmology, SKIMS Medical College \\ Srinagar
}

\section{A B S T R A C T}

BACKGROUND: Pseudoexfoliation syndrome (PXS) is the most common identifiable cause of secondary glaucoma with a considerable variability in its prevalence among different ethnicities.

OBJECTIVE: To study the Prevalence of Pseudoexfoliation Glaucoma and PXS in South Kashmir.

METHODS: In this Hospital-based study, all consenting patients, 45 years or older, presenting to out-patient ophthalmology department of a sub-district hospital in South Kashmir from August 2011 to May 2012 were enrolled. All subjects underwent a complete ophthalmological evaluation as per a standard protocol.

RESULTS: The prevalence of PEXS was found to be $7.10 \%$ and PEX glaucoma to be $3.10 \%$. PXS was bilateral in $84.5 \%$ of the cases. There was age-related increase in prevalence of PEX from prevalence of $2.80 \%$ in less than 50 years to prevalence of $10.80 \%$ in above 70 years. $48.35 \%$ of the case of PEXS had glaucoma.

CONCLUSIONS: PXS and PEX glaucoma is quite common in middle-aged and older subjects of South Kashmir. Early detection of such cases can prevent loss of vision due to glaucoma in affected subjects. JMS 2012;15(1):51-53.

Key Words: Pseudoexfoliation syndrome, glaucoma, blindness

Glaucoma is the second leading cause of blindness worldwide and the number of Glaucoma cases are expected to hit 80 million by 2020. ${ }^{1}$ Pseudoexfoliation syndrome (PXS) is the most common identifiable cause of secondary glaucoma, the prevalence of which varies considerably among different ethnicities. ${ }^{2}$ Pseudoexfoliation (PXF) is an age-related disorder characterized by the accumulation of a fibrillar extracellular material in ocular tissues and is often associated with glaucoma. Glaucoma secondary to PEX syndrome often is far advanced when diagnosed and is difficult to control medically.

\section{Correspondence:}

Dr Asif Amin Vakil

House 9, Lane 4, Haider Enclave,

Khan Factory Lane, Srinagar, Kashmir

E-Mail: drasifaminvakil@yahoo.com

Phone: +919419873468
Since its first description by Lindberg in 1917, PEX syndrome has been documented in most populations. ${ }^{3}$ It is most common in patients of Scandinavian heritage and is relatively uncommon among African-Americans. PEX syndrome is more common in women, although this observation may occur as a result of bias because of the longer life span of women. The prevalence of PEX syndrome increases markedly with age. ${ }^{4}$ The condition may occur bilaterally, but almost one half of the cases appear to be unilateral at the time of diagnosis.

Prevalence of Pseudoexfoliation syndrome and in Kashmir valley is not known. In the present study, we are reporting the prevalence of PXS and PXS-glaucoma in subjects 45 years or older, presenting to out-patient ophthalmology department of a sub-district hospital in South Kashmir. 


\section{Methods}

This Hospital based study was performed in the Ophthalmology OPD at a Sub District Hospital in South Kashmir. All the patients who were 45 years of age or older presenting to Out Patient Department from August 2011 to May 2012 were asked to enrol for this study. After informed consent the patients underwent a complete ophthalmological evaluation. All the patients underwent detailed examination including Visual acuity assessment, Slit-lamp biomicroscopy, Applanation tonometery, Gonioscopy and a detailed fundus examination. Patients were referred to higher centre for visual field assessment to evaluate the baseline damage to visual fields and to monitor progression of the disease. A detailed fundus examination was done for cup-disc ratio.

The criterion used to diagnose PXS was the presence of pseudoexfoliatory material on one or more anterior segment structures while as, the Criterion for diagnosing PEX Glaucoma was the presence of pseudoexfoliatory material on one or more anterior segment structures and raised intraocular pressure in presence of glaucomatous cupping of optic nerve head and loss of neuroretinal rim and / or Visual field defects compatible with glaucoma. The exclusion criterion was the concomitant congenital eye diseases, or previous medical, surgical or laser treated eyes. Subjects who were psuedophakic or aphakic in any eye were also excluded from the study.

\section{Results}

Age of the subjected ranged from 45 to 89 years (Table 1). Majority of the subjects were in the age group of 50-59 years (Table 2). The prevalence of PEXS was found to be 7.10 $\%$ and PEX glaucoma to be $3.10 \%$ (Table 3 ). Clinical features of PXS included pseudoexfoliation of lens, flakes of the iris margin, poor pupil dilatation, iris anamolies, flakes of the TM, high IOP, and Zonular Weakness (Table 4). PXS was bilateral in $84.5 \%$ of the cases. There was age-related increase

Table 1. Demographic Details of the study population

\begin{tabular}{lccc} 
Characteristic & $\begin{array}{c}\text { All patients } \\
(n=3000)\end{array}$ & $\begin{array}{c}\text { PXS } \\
(n=213)\end{array}$ & $\begin{array}{c}\text { PEX G } \\
(n=103)\end{array}$ \\
Age range (years) & $45-89$ & $46-86$ & $46-86$ \\
Gender ratio (M:F) & $1.2: 1$ & $1.1: 1$ & $1.3: 1$ \\
Mean Visual acuity & $6 / 12$ & $6 / 18$ & $6 / 36$ \\
\hline
\end{tabular}

Table 2. Age Distribution of the studied population

$\begin{array}{lcc}\text { Age group (Years) } & \text { No. of Subjects } & \text { Percentage } \\ 40-49 & 542 & 18.1 \\ 50-59 & 921 & 30.7 \\ 60-69 & 729 & 24.3 \\ 70 \text { and above } & 808 & 26.9\end{array}$

Table 3. Prevalence of PEXS and PEXG stratified according to age group

\begin{tabular}{lcccccccc} 
Age group & \multicolumn{3}{c}{ PEX Syndrome } & & \multicolumn{3}{c}{ PEX Glaucoma } \\
\cline { 3 - 4 } \cline { 7 - 8 } (years) & $n$ & $\%$ & Prevalence & & $n$ & $\%$ & Prevalence \\
$40-49$ & 15 & 7.04 & $2.8 \%$ & & 5 & 4.8 & $0.9 \%$ \\
$50-59$ & 48 & 22.53 & $5.2 \%$ & & 26 & 25.2 & $2.8 \%$ \\
$60-69$ & 62 & 29.12 & $8.6 \%$ & & 29 & 28.2 & $4.0 \%$ \\
$\geqslant 70$ & 88 & 41.31 & $10.9 \%$ & & 43 & $41.8 \%$ & $5.3 \%$ \\
All groups & 213 & 100 & $7.1 \%$ & & 103 & $100 \%$ & $3.4 \%$ \\
\hline
\end{tabular}

in prevalence of PEX from prevalence of $2.80 \%$ in less than 50 years to prevalence of $10.80 \%$ in above 70 years. $48.35 \%$ of the case of PEXS had glaucoma.

\section{Discussion}

PEX material has been detected by electron microscopy

Table 4. Clinical Features of patients with PXS

\begin{tabular}{lc} 
Clinical features & $\mathrm{N}(\%)$ \\
\hline Pseudoexfoliation of lens & $207(97.2)$ \\
Flakes of the iriss Margin & $198(93.0)$ \\
Poor pupil Dilatation & $162(76.1)$ \\
Iris anamolies & $132(62.0)$ \\
Flakes of the & TM121(56.8) \\
High IOP & $103(48.4)$ \\
Zonular Weakness & $30(14.1)$ \\
Bilateral Cases & $180(84.5)$ \\
\hline
\end{tabular}

in the conjunctiva of fellow eyes which have no apparent PEX based on biomicroscopic examination. Presumed unilateral cases most likely represent asymmetrical, bilateral cases. $25 \%$ of patients who have unilateral PEX syndrome develop the disease in the fellow eye within 10 years. The lysyl oxidaselike protein 1 (LOXL1) gene is important for elastin metabolism. Defects in elastin metabolism have been postulated to result in synthesis of pseudoexfoliative material. It has been shown that specific mutations of the LOXL1 gene are strongly associated with the development of PEX and secondary glaucoma. PEX syndrome is a systemic disorder, although its clinical relevance, based on current knowledge, is limited primarily to its ocular manifestations. PEX material has been identified in many visceral organs, as well as in the eye. ${ }^{5,6}$ PEX material contributes to the accumulation of pigment and debris within the aqueous outflow channels which overwhelms the system resulting in increased resistance to aqueous outflow, damage to the juxtacanalicular region and Schlemm's canal, and subsequent increased IOP. Orbital blood flow velocities by Doppler imaging have shown a significant reduction in peak systolic and diastolic velocities in the short posterior ciliary arteries, central retinal artery, and the ophthalmic artery, as well as increased mean resistance in patients with PEX glaucoma. ${ }^{7}$ 
The prevalence of PEXS was found to be $7.10 \%$ and PEX G to be $3.10 \%$. The prevalence rate of PEX Syndrome has been reported variedly in different population groups The prevalence rate of PEX syndrome has been reported to be $0 \%$ in Eskimos, ${ }^{8} 1.8 \%$ in the United States, ${ }^{9} 5-25 \%$ in the Scandinavian countries. ${ }^{9}$ Population-based studies from South India have reported the prevalence of PXF to be between $3.8 \%$ and $6.0 \%$ among persons aged $\geq 40$ years. ${ }^{10,11}$ The majority of Kashmiri population depends heavily on the agricultural sector for employment and income and would be exposed to outdoor activities in a routine way that may constitute a significant risk factor for the occurrence of PEX in this population. The study shows there is age related increase in prevalence of PEX from prevalence of $2.80 \%$ in less than 50 years to prevalence of $10.80 \%$ in above 70 years. Previous studies have shown a marked age-related increase in the prevalence of PXF; typically $<1 \%$ in persons younger than 60 years and increasing to $6.28 \%$ among subjects 60 years of age or older. ${ }^{10,12}$ Although the reason for this agerelated increase is unknown, it has been speculated that the changes in gene expression that occur with age may be responsible. ${ }^{13}$ There are conflicting reports of gender differences in the prevalence of PXF. ${ }^{14,15}$ It was also noted that the PXS was bilateral in $84.5 \%$ of the cases which is high as compared to other studies. However, as shown by Prince et al and Speakman et al, the disease is invariably bilateral pathologically. ${ }^{16,17}$ It was found the prevalence of PXF among men to be marginally higher than in women. Most of the studies have shown prevalence of high intraocular pressure with or without glaucoma to be in between $22 \%$ to $30 \%$.In our study $48.35 \%$ of the case of PEXS had glaucoma. It is quite possible that this high rate in the study may be due do the design of study which was hospital based.

\section{References}

1. Quigley HA, Broman AT. The number of people with glaucoma worldwide in 2010 and 2020. Br J Opthalmol 2006;90: 262-7.

2. Ritch R. Exfoliation syndrome: clinical findings and occurrence in patients with occludable angles. Trans $A m$ Ophthalmol Soc 1994;92:845-44.

3. Forsius H. Exfoliation syndrome in various ethnic populations. Acta Ophthalmol 1988;66:71-85.

4. Liebowitz HM, Krueger DE, Maunder LR. The Framingham Eye Study Monograph. Surv Ophthalmol 1980;24(Suppl.):335-610.

5. Schlotzer-Schrehardt UM, Koca MR, Naumann GO, et al. Pseudoexfoliation syndrome. Ocular manifestation of a systemic disorder. Arch Ophthalmol 1992; 110:1752-6.

6. Streeten BW, Li ZY, Wallace RN, et al. Pseudoexfoliative fibrillopathy in visceral organs of a patient with pseudoexfoliation syndrome. Arch Ophthalmol 1992; 110:1757-62.

7. Yuksel N, Karabas VL, Arslan A, et al. Ocular hemodynamics in pseudoexfoliation syndrome and pseudoexfoliation glaucoma. Ophthalmology 2001; 108(6):1043-9.

8. Hiller R, Sperduto RD, Krueger DE. Pseudoexfoliation, intraocular pressure, and senile lens changes in a population based survey. Arch Ophthalmol 1982;100:1080-2.

9. Forsius H. Prevalence of pseudoexfoliation of the lens in Finns, Lapps, Icelanders, Eskimos and Russians. Trans Ophthalmol Soc UK 1979;99:296-98. 